\title{
Exploring excellence in Indigenous education in Queensland secondary schools
}

\author{
Dr Marnee Shay \\ The University of Queensland \\ Dr Jodie Miller \\ The University of Queensland \\ Dr Suraiya Hameed \\ The University of Queensland \\ https://doi.org/10.37517/978-1-74286-638-3_8
}

Dr Marnee Shay is an Aboriginal researcher, with maternal connections to Wagiman country and strong ties to Aboriginal communities in south-east Queensland where she was born and raised. Having a diverse professional background, she has worked in the community sector as a youth worker and as a classroom teacher in secondary schooling and tertiary contexts. Dr Shay is nationally recognised for her leadership in education research. She is an interdisciplinary researcher who has been awarded multiple externally funded projects across the fields of Indigenous education, youth studies and policy and practice.

Dr Jodie Miller is a non-Indigenous education researcher working as a Senior Lecturer at the University of Queensland. Prior to working in universities Jodie was a primary classroom teacher. Her research area focuses on improving the teaching and learning of mathematics, particularly for students who are most at risk of marginalisation from the school mathematics curriculum. In addition to this, her recent research collaborations focus on examining excellence in Indigenous education.

Dr Suraiya Hameed is a Lecturer in Educational Leadership at the University of Queensland. She has Indigenous Malay ethnic roots, on her maternal side within the Singaporean context. She has been in education for 30 years and was previously a school leader before transitioning into a lecturing and research position at UQ. Her research interests are in exploring complex educational issues - from shifts in cultural practices and racial, ethnic, and linguistic diversity to the implications of these shifts for human or social development and education. Her current research focus is within the area of leadership, global citizenship \& inclusive education specifically in the area of Indigenous education.

\section{Abstract}

In the national and international landscape, there is very limited exploration of cultural constructs of excellence, in particular, in Indigenous contexts. This pilot study aimed to centre the voices of Indigenous people in conceptualising excellence in Indigenous education, as well as to share understandings between Indigenous and non-Indigenous practitioners. Qualitative data collection methods were used including collaborative yarning, storying, and semi-structured interviews. Data were analysed using cross-case analysis to examine the views of educators across three school sites. Indigenous participants highlighted the importance of nurturing culture and identity; building up young people; and, building a culture of inclusivity and belonging. Supportive leadership was also identified as an enabler for enacting excellence in schools. A direct outcome of this project was a whole-school policy that builds on a strengths perspective and forefronts the embedding of Indigenous knowledges and perspectives, supporting the wellbeing of Indigenous students, affirming the identities of Indigenous students and having specific strategies to engage with local Indigenous communities. 


\section{Introduction}

The terms 'Indigenous education' and 'excellence' in Indigenous education are so conceptually distanced, that when we commenced this project, a good search of the two terms yielded little information. The distance between these concepts in scholarly and policy domains demonstrates the depth and pervasiveness of deficit discourses in Indigenous education in Australia. The term excellence has emerged from Indigenous communities within Australia as a way of recognising and acknowledging strengths, knowledges and values of Indigenous peoples and communities in the face of the persistence of deficit narratives in social, political and educational discourses. In small pockets of social media or in the naming of various educational programs, for example, the term Indigenous excellence is operationalised by Indigenous peoples in various contexts. We have attempted to understand what Indigenous education excellence is and the ways in which it is conceptualised by centring Indigenous voices but also including the voices in education who are responsible for enacting Indigenous education policies: principals, teachers and education workers. It is important to distinguish that we are not defining Indigenous excellence; we are exploring the concept of excellence in the many elements that make up Indigenous education practices.

A synthesis of the literature that focuses on Indigenous learners in schools revealed six key themes where research is focused: these predominantly cover issues on identity, cultural competence of educators, engaging with Indigenous families and communities, presence of Indigenous cultures in schools, employment of Indigenous peoples in schools, and leadership (Shay \& Heck, 2016). There is also increasingly a focus on the embedding of Indigenous knowledges and perspectives into curriculum; advocating the need for it, critical discussion about the contestability of Australian histories and the ability to embed across all curriculum areas, and these have all emerged in national discussions on the issue (Phillips \& Lampert, 2012; Sarra, 2011; Smith et al., 2019; Sarra \& Shay, 2019).

The concept of excellence in education is relatively undertheorised. Walker (1996) highlights complexities in understanding the term in relation to the subjectivities in how the term excellence is defined, understood and applied. The use of the term excellence broadly in education has often lacked a holistic view of what it can include and emphasises academic merit over other educative endeavours and outcomes. The OECD states clearly that the promotion of 'excellence, equity and inclusion are key aims for education' (Schleicher, 2014, p. 11) and is a priority for the global community. However, measurement of excellence undertaken through PISA (Programme for International Student Assessment) is through testing students on their science, maths, reading, collaborative problem-solving skills and financial literacy capability (OECD, 2018). In the national and international landscape, there is very limited exploration of cultural constructs of excellence, in particular, in Indigenous contexts.

\section{Background}

This paper shares key findings from a pilot study, 'Doing things right way: Dimensions of excellence in Indigenous education in Queensland secondary schools'. This project was led by Aboriginal researcher Shay, Miller (non-Indigenous Australian researcher, and Hameed (an Indigenous researcher from Singapore). We explored what excellence in Indigenous education is or could be. This study aimed to centre the voices of Indigenous people in conceptualising excellence in Indigenous education, as well as to share understandings between Indigenous and non-Indigenous practitioners. 
The following research questions were used to study participants' conceptualization and enactment of excellence at school level.

1. How is excellence in Indigenous Education defined by Indigenous educators and community leaders?

2. What are some examples Indigenous educators and community leaders identify as excellence in Indigenous Education?

3. What do Indigenous educators and community leaders indicate as ways leaders can support the enactment of excellence in Indigenous education?

The pilot study explored dimensions of excellence in Indigenous education and demonstrated the need to examine the topic of excellence in Indigenous education in a wide variety of contexts where Indigenous education is being practised (Shay \& Miller, 2019). The key findings demonstrated that the two terms 'excellence' and 'Indigenous education' have been so conceptually distanced that both Indigenous and non-Indigenous participants often reverted back to discourses of gaps and deficits even when being explicitly asked what excellence in Indigenous education is or could be.

\section{Methodology}

This was a qualitative study, with a collective case study methodology underpinning the design of the project, allowing for an in-depth understanding of the phenomenon and multiple examples that are contextualized and localized (Punch, 2013). Cross-case analysis was conducted to sieve out similarities and differences in the way the schools are interpreting and realising Indigenous education excellence. Emergent meta-level conceptual themes on Indigenous education excellence were discussed: enablers and constraints; and the relevance of distinctions between Indigenous excellence and academic achievement were also addressed.

Qualitative data from various means were collected. A number of methods were used in storying the case studies. The use of yarning, an Aboriginal conversational style of sharing knowledges and experiences (Bessarab \& Nga'ndu, 2010) were utilised to develop ways of identifying and understanding excellence in Indigenous education with both Indigenous and non-Indigenous participants. Yarning in documenting the case study from multiple perspectives included semiformal questions about the practice, collaboration with Indigenous peoples in the process, the resourcing required, and enablers. Data were recorded using a methodology developed by Shay (2019), known as collaborative yarning methodology. Recording of yarns via a storyboard enables a more culturally relevant and ethical way of incorporating diverse Indigenous voices.

The theoretical lens used is based on Rigney's Indigenist principles of political integrity (2001), resistance as the emancipatory imperative and privileging of Indigenous voices in the conceptual framing of Indigenous research. While the data include the perspectives of non-Indigenous researchers (who make up the majority of the education workforce), the research design ensured there were mechanisms to aim for at least half of all participants to be Indigenous, ensuring that Indigenous peoples' perspectives, stories, experiences and aspirations were central in conceptualizing what Indigenous education excellence is or could be. Specific analysis to foreground the voices of Indigenous perspectives across all research questions was informed by Rigney's Indigenist principles (2019). 


\section{Discussion}

Indigenous participants in this Study described their conceptualisations of excellence in Indigenous education within three key areas: nurturing culture and identity; building up young people; and, building a culture of inclusivity and belonging. Other themes that surfaced included an emphasis on relationships, supporting young people to achieve goals, and walking together.

It was clear in the data that exploring Indigenous education through a lens of excellence was a foreign notion to some participants. Our analysis suggests that this was due to the prevailing deficit discourses that exist in policy, scholarship and practice and these discourses have also been absorbed by Indigenous peoples in education settings (though to a lesser extent). As this research is original in concept, these initial findings suggest that growing this data set will assist in producing a broader understanding and will assist in theorizing what Indigenous education excellence is or can be in Australia. The implications for this Study are far reaching, as educational parity for First Nations students globally remains a critical social justice issue.

Another key finding within the study is the important role that leadership plays in the enactment of excellence in schools. The findings from the literature review and also the empirical research conducted showed that there is a need for school leaders who are cognisant of the importance of providing a conducive environment that respects and values Indigenous knowledges, have high expectations for Indigenous students' achievements and most importantly encourage meaningful and culturally responsive pedagogical practices that assist in the building of a strong culture and enhance learning and involvement for Indigenous students (Hameed, Shay \& Miller, 2021).

Many Indigenous educators also discussed the importance of having supportive school leaders who provided them with opportunities to lead in their school communities. What became apparent through our yarning sessions was the importance of leaders' embedding Indigenous education, culture and histories into the life of the school. Leaders needed to be serious about: 1) embedding this into their school policy documents; 2) moving beyond singular occurrences in school life; and, 3 ) creating a sustainable ongoing commitment to acknowledging and supporting Indigenous young people in their schools (Hameed, Shay \& Miller, 2021).

\section{Developing a school-wide policy framework}

To support educational leaders in developing a school-wide policy framework for implementing Indigenous education, Shay \& Miller (2021) published a chapter in the book Building better schools with evidence-based policy (Allen et al., 2021). The school-based policy is informed by strengths approaches and data developed through this Study. This chapter intentionally employs language that shifts away from notions of 'closing the gap' to endorsing existing research connected to key findings from our Study about how excellence in Indigenous education was conceptualised. Key features of the policy include intentions of embedding Indigenous knowledges and perspectives, supporting the wellbeing of Indigenous students, affirming the identities of Indigenous students and having specific strategies to engage with local Indigenous communities. 


\section{References}

Allen, K.-A., Reupert, A., \& Oades, L. (Eds.). (2021). Building better schools with evidencebased policy: Adaptable policy for teachers and school leaders. Routledge. https://doi. org/10.4324/9781003025955

Bessarab, D., \& Ng'andu, B. (2010). Yarning about yarning as a legitimate method in Indigenous research. International Journal of Critical Indigenous Studies, 3(1), 37-50.

Hameed, S., Shay, M., \& Miller, J. (2021, forthcoming). Deadly leadership in the pursuit of Indigenous education leaders. In Future alternatives for educational leadership: Diversity, inclusion, equity, and democracy. Routledge.

Phillips, J., \& Lampert, J. (2012). Introductory Indigenous studies in education (2nd ed.). Pearson.

Punch, K. (2013). Introduction to social research: Quantitative and qualitative approaches. Sage.

Rigney, L. (2001). A first perspective of Indigenous Australian participation in science: Framing Indigenous research towards Indigenous Australian intellectual sovereignty. Kaurna Higher Education Journal, 7, 1-13.

Sarra, C. (2011). Strong and smart - Towards a pedagogy for emancipation: Education for first peoples. Routledge.

Sarra, G., \& Shay, M. (2019). Indigenous education, critical perspectives to enhance learning practices. In Encyclopedia of teacher education (pp. 1-8). Springer. https://doi: 10.1007/978-98113-1179-6_195-1

Schleicher, A. (2014). Equity, excellence and inclusiveness in education: Policy lessons from around the world. OECD.

Shay, M. (2019). Extending the yarning yarn: Collaborative yarning methodology for ethical Indigenist education research. The Australian Journal of Indigenous Education, 1-9. https://doi.org/10.1017/ jie. 2018.25

Shay, M., \& Heck, D. (2015). Alternative education engaging Indigenous young people: Flexi schooling in Queensland. The Australian Journal of Indigenous Education, 44(1), 34-47. https://doi: 10.1017/ jie.2015.8

Shay, M. \& Miller, J. (2019, December 1-5). Doing things right way: Dimensions of excellence in Indigenous education in Queensland secondary schools [Paper presentation]. Australian Association for Research in Education, Brisbane, QLD, Australia.

Shay, M. \& Miller, J. (2021). Excellence in Indigenous education. In K.-A. Allen, A. Reupert \& L. Oades (Eds.). Building better schools with evidence-based policy: Adaptable policy for teachers and school leaders (pp.46-54). Routledge.

Smith, L., Tuck, E., \& Yang, K. W. (2019). Indigenous and decolonizing studies in education: Mapping the long view (Indigenous and decolonizing studies in education). Routledge.

OECD. (2018). Programme for International Student Assessment. www.oecd.org/pisa/aboutpisa

Walker, R. (1996). Excellence with decency. Equity and excellence in education, 29(1), 97-101. 